\title{
Bottom Sediments of Port au Port Bay, Newfoundland*
}

\author{
J. I. SHEARER
}

Memorial University of Newfoundland, St. John's, Nfld.

\section{Progress Report}

During the summer of 1966, in shore marine geological study was undertaken in Port au Port Bay on the west coast of Newfoundland adjacent to the Gulf of St. Lawrence. To date the size distribution and mineralogy of some of the bottom sediment samples, beach samples and pleistocene glaciofluvial samples have been analyzed. In particular, a detailed analysis of the probability plots of the size distribution of each sample is being made in an effort to fractionate the sample into its component parts. This is done by using the method of finite differences proposed by W.F. TANNER (1959). The main assumption here is that a log-normal probability curve is representative of a population in equilibrium with a particular environment and, therefore, 'a fundamental population of that environment, whereas a zig-zag log probability curve is caused by mixing in given proportions of two or more fundamental log-normal populations.

In this respect, with the few samples (about 30) examined in Port au Port Bay, it has been found that many of them which,possess dissimilar probability plots are composed of essentially the same fundamental populations of silt, fine sand, coarse sand and gravel, but with the relative proportions of each fundamental population varying from sample to sample. Before a reasonable idea of the significance of these relative changes in abundance of fundamental populations can be obtained, more samples must be examined. As well as this type of analysis, the regular statistical parameters of mean, standard deviation, skewness and kurtosis are being worked out using the arithmetic method of moments.

So far, both types of analyses indicate that much reworking of the sediments in the Bay have taken place and, in fact, under the sea no vestiges of the original glacial till remain. It has been presumed, that, in the dying stages of Wisconsin glaciation, till was deposited in the Bay at a time when the latter stood above sea level and since that time, with the subsequent rise in sea level due to the melting of the glaciers, the encroaching sea has caused reworking of this original till. Complicating this picture is the past and present isostatic rebound of the land, which is reworking the previously reworked till.

Mineralogical studies have to date indicated that the recent sediments in Port au Port Bay are composed mainly of an acid type mineral suite, but that near shore this suite is mixed with, and diluted by, basic minerals from nearby ultra-basic outcrops. Presumably most of this basic material is introduced fluvially and from direct erosion of the sea on raised post-Wisconsin terraces.

\section{References cited}

TANNER, W.F.; 1959, Sample components obtained by the method of differences: Journal Sedimentary Petrology, vol. 29, pg. 408-411. 